\title{
Re-Envisioning Evaluation Pedagogy with a Community of Scholar Teachers
}

\author{
Jill Anne Chouinard \\ University of Victoria \\ John M. LaVelle \\ University of Minnesota-Twin Cities
}

\begin{abstract}
"[The] educator must be awake, critical, open to the world. It is an honor and a responsibility to be a teacher in such dark times-and to imagine, and to act on what we imagine, what we believe ought to at last be"

(Maxine Greene, 2005, p. 80).

"It is crucial that critical thinkers who want to change [their] teaching practices talk to one another, collaborate in discussion that crosses boundaries and creates a space for intervention"
\end{abstract}

(bell hooks, 1994, p. 129).

This special volume is motivated by our interest in the pedagogy of evaluation, in an ongoing concern with how best to teach evaluation to novice evaluators without reducing the field to a set of techniques. Ultimately our goal with this volume is to contribute to a dialogue about teaching evaluation and to build an active, engaged community of scholar teachers, what bell hooks (1994) might call "a community of learners" (p. 153). Our goal is not to identify "best practices" in terms of teaching evaluation, a problematic term that implies some type of shared standard regardless of context (Calliou \& Wesley-Esquimaux, 2015), but rather something more modest: to provide the opportunity for scholar teachers to share the diversity of their pedagogical practices, as well as their reflections on the challenges, opportunities, and complexities such teaching inevitably entails. We did not direct them about what to write; we simply asked that they share creative or innovative teaching practices that they have developed or used in the classroom, practices that they felt were pedagogically novel.

The format of the practice note is ideal, as it provides the opportunity for authors to describe their innovative approaches to teaching and to critically reflect on their experiences. Following this format, each of the articles remains under 3,000 words, with each providing a brief description of a teaching innovation, followed by key reflections on practice. Taken together, these articles highlight the multiple and diverse approaches, styles, locations, and contexts of teaching, whether enacted in a classroom, online, in professional workshops or through

Corresponding author: Jill Anne Chouinard, School of Public Administration, University of Victoria, PO BOX 1700 STN CSC, Victoria, BC V8V 2Y2; jchouinard@uvic.ca 
community engagement during an evaluation or evaluation practicum. The range of topics and pedagogical approaches and strategies illustrates the multiplicity of roles, perspectives on evaluation, values, and philosophical positions held by evaluators across the breadth of the field. In this concluding chapter, we synthesize the key pedagogical approaches, strategies, concerns, and aspirations described by the contributors to this volume, focusing our synthesis on key pedagogical moments. Beyond this, this concluding article challenges the community of scholar teachers to think about the ethical, cultural, political, and philosophical implications of their pedagogical practices in evaluation.

In looking across all of the 15 articles, it seems clear that our colleagues all share extensive ambitions and hopes for the field, as well as a willingness to challenge the use of existing methods and techniques, and to portray evaluation as more than an extractive science. A number of the articles focus on the "liberatory potential" (Archibald, p. 315) of the field, a shift away from methodological or procedural technique toward evaluative thinking, critical reflection, mentoring, social justice, decolonization, or disruption (e.g., Archibald; Arias Orozco et al.; Bowman; Boyce; Chapman et al.; Gokiert et al.; LaVelle \& Yang). Others focus their articles on the use of assessment scales to measure the acquisition of skills and learning, as well as descriptions of models to encourage deeper reflection (e.g., Pitts; Searle \& Poth; Smith). Still others turn to competency-based approaches to ensure learning and the development of evaluator dispositions (e.g., Davies; LaVelle \& Yang; McDavid \& Shepherd; Poth \& Searle). We also note a significant focus on interpersonal relationships, whether among students, faculty, and clients (or a mix therein) or between students working together in collaborative arrangements with clients or together on class projects (e.g., Lovato \& Graham; Montrosse-Moorehead; Smith). Some of the contributors focus on case-based learning approaches (e.g., Archibald; Gokiert et al.), with others highlighting student fieldwork in their engagement with external clients (e.g., Arias Orozco et al.; Montrosse-Moorehead; Searle \& Poth). There is also substantial emphasis on reflective practice, whether within the classroom among students and faculty, or individually, as scholar teachers seek a deeper level of analysis and personal reflection on their own teaching and on the pedagogy of evaluation (e.g., LaVelle \& Yang; Lovato \& Graham; Pitts; Searle \& Poth; Smith). Finally, we also note struggles in adapting Western models in nonWestern contexts and in shifting emphasis from the academy to the community (e.g., Archibald; Arias Orozco et al.; Bowman; Chapman et al.).

In the space between theory and practice, the line between the classroom (virtual or in-person, synchronous or asynchronous) and the world is redrawn through reflection, action, and engaged praxis. Freire (1970) makes an important distinction between what he calls the "banking concept of education," where students are considered empty vessels that need filling, and "problem-posing education," where students and teachers become co-learners or co-investigators in a process of critical dialogue and reflection. This latter approach to education is based on the values of creativity, engagement, collaboration, reflective practice, and dialogue, all of which are essential in a field as culturally and philosophically 
diverse and dynamically complex as evaluation. Notions such as problem-posing education and critical reflection are quite apparent in all of the practice notes, as contributors seek to make meaning out of their teaching and student learning experiences, and in their struggle to bridge what they describe as a shift from theory to practice. While we acknowledge the many potential interpretations and understandings in the diverse contributions of this volume, in what follows we describe four broad themes that we feel capture the pedagogical essence of the volume.

\section{REVISIONING EVALUATION}

One of the central concerns in the pedagogy of evaluation is the tension between cultivating a critical, moral, political, and reflective capacity while still providing the technical knowledge and skills required in evaluation practice (Schwandt, 2015). While this tension is not made explicit in the articles, the majority of contributors emphasize the less tangible and more difficult to measure aspects of the field, such as interpersonal skills, evaluation dispositions, collaboration, and reflective capacity. With the acknowledgement that "good evaluators are more than methodological technicians" (p. 391), Montrose-Moorehead brings the focus of her practice to the development of interpersonal skills and the need for building trusting relationships. For international students (see Arias Orozco et al.), their concerns are not technical in nature, but focused on understanding program context, communication, and language. After one year of evaluation instruction, the students reflect:

... we consider openness, flexibility, and humility to be key components of our profession, and essential in enabling us as international students to address the many challenges we experienced. Evaluation work requires us to reflect on and be aware of our cultural identity in order to ground our positionality, assumptions, and biases. (Arias Orozco et al., p. 418).

For Archibald, evaluative thinking provides a bridge between theory and practice, a way to engage learners in a philosophical reflection about methodological assumptions as well as about the moral and political implications of evaluation practice. Davies, for his part, engages students in discussion about competencies and connections to evaluator dispositions (beliefs and values), highlighting the associated ethical, cultural, and personal tensions, especially given the lack of consensus on such issues in our field. In her article, Bowman seeks to reposition evaluation from its current location as an "expressway to information generation" to a "pathway to wisdom," to a critical revisioning of evaluation and evaluation pedagogy as a deeply reflective practice on self, knowledge construction, and impact on other communities. In her article on mentoring students of colour, Boyce builds upon Ladson-Billings's concept of culturally relevant pedagogy to highlight the interrelated concepts of self/others, social relationships, and knowledge as essential in mentoring relationships. Other contributors to this volume also focus their pedagogies on teaching aspects of evaluation that are not often found in the "toolkit," such as communication, trust, vulnerability, relationship building, 
and so on (e.g., Chapman et al.; Lovato \& Graham; Searle \& Poth; Smith). As Archibald summarizes, "as important as these technical competencies are, they remain secondary to understanding the conceptual and even philosophical underpinnings of evaluation practice" (p. 313).

\section{PEDAGOGY AS TRANSFORMATION}

In the articles, we also note the active engagement of students as central participants in their own educational experience. Contributors eschew a top-down approach to teaching, in favour of one where students and teachers together engage (often with community members) in constructing and reconstructing the pedagogical landscape. The classroom thus becomes, as hooks (1994) describes, "a location of possibility" (p. 207). This change, while mirroring a pedagogical shift in education more generally, mirrors a fundamental transformation in evaluation practice, where participants evolve from the position of "subject" to that of "participant" in the knowledge-construction process. In their struggle to create a meaningful and culturally appropriate context for teaching evaluation in an African setting, Chapman et al., create what they refer to as a "model client" approach to pedagogy. In this approach, the client, whose project students are working on, joins the class and becomes an active and important participant (a co-evaluator) along with students and the instructor. As Chapman et al. state, "in teaching evaluation, pluralistic teaching and learning approaches (e.g., coursework, mentorship, peer exchanges) are similarly recognized as part of the broader process to develop, reinforce, and sustain different evaluation competencies that underlie strong evaluation practice" (p. 378). Gokiert et al., for their part, create a constructivist pedagogy as a way to promote peer learning between faculty, students, funders and community partners. As they state, "rather than students going into the community for practicums or community service learning, UEval brings the community to the classroom" (p. 287). Similarly Searle and Poth use a collaborative classroom design that focuses on the quality of relationships both inside and outside the classroom, as well as outside, with clients. Smith highlights good communication skills as essential in evaluation, stating "setting up the learning environment as a lateral space for open communication sets the stage for more authentic reflection on how we go on together" (p. 409). Notwithstanding the online format of their courses, McDavid and Shepherd strive to create an online learning environment that engages students in what they refer to as "deep learning" based on multiple techniques and approaches developed according to the principles of adult learning. Using a competency-based teaching approach, Poth and Searle strive to ensure that students become active participants in their own learning, building learnercentred choices and metacognitive practices into their pedagogy.

\section{CULTURAL TENSIONS}

A number of contributors (e.g., Arias Orozco et al.; Bowman; Boyce; Chapman et al.) challenge the cultural dominance of Western methodological approaches to 
evaluation theory and practice, arguing for a shift to local knowledge and to a more culturally responsive pedagogy. For Chapman et al., the "model client" is intended to bring a more "made in Africa" approach to the classroom and to the curriculum, a shift in power dynamics to encourage shared perspective between client, students, and faculty. For Boyce, the use of culturally relevant pedagogy for mentoring relationships with students of colour brings a focus to students' cultural context, as a way to ensure cultural integrity through centring the teacherstudent relationship, as well as an appreciation of epistemological and pedagogical plurality. Culturally relevant pedagogy calls on the teacher (or mentor) to consider the impact of trauma, building mutual peer support for students, respecting and honouring students' culture, religion, and family values, acknowledging microaggressions when they occur, and developing mentoring competence as it relates to issues of diversity. In her practice note, Bowman, an Indigenous, self-described "blue collar scholar," speaks to the cultural and privileged location of evaluation scholars and practitioners in the academy, arguing for the need to decentre and decolonize our pedagogical practices through a process of critical self-analysis and critically engaged praxis. For their part, as international students, Orzco et al. are keenly aware of the challenges they might experience applying Westernbased methodologies and understandings in their home contexts. Their advice to teachers of evaluation is to develop an awareness of cultural differences and to "look beyond the application of their frameworks and perspectives to understand that there is not one unique approach for doing evaluation, but many, depending upon the program and its cultural context" (p. 418).

\section{DYNAMIC AND REFLECTIVE PRACTICE}

A final theme that echoes through all the practice notes is the use of critical, purposeful reflection, what Freire (1970) might consider a form of engaged pedagogy or praxis (reflection and action in the world in order to change it). Reflexive practice, as Arias Orozco et al. state, "can help us navigate complex contexts" (p. 418). As Bowman makes clear in her article, praxis begins with self, with critical self-reflection about the impact of our own ways of thinking and interacting. For Archibald, evaluative thinking becomes a catalyst for reflective practice on four levels: in terms of the role evaluation plays in broader society, at the level of self-knowledge, in terms of "reflection-in-action" (see Argyris, 2004), with connections to values, social justice, and critical praxis, and as meta-reflective activity. Others build reflective practice into their evaluation curriculum, encouraging students to complete reflections on their learning experiences, competencies, major course learnings, and collaborative and online group processes (e.g., Davies; Gokiert et al.; LaVelle \& Yang; McDavid \& Shepherd). For some, reflection is initiated through the development of specific instruments for use by students as a way to measure applied learning and "optimize" evaluator education (e.g., Lovato \& Graham; Searle \& Poth; Smith). For Lovato and Graham, the focus of the practice note is on the use of an instrument called "Team Performance Scale," which they use to help students reflect on the behaviours of high-performing 
teams. Searle and Poth, for their part, integrate a type of "authentic assessment" into their collaborative design as a way to focus on the learning process, and integrate feedback and reflection into the learning process. For others, individual reflections on learning experiences (e.g., Pitts) and the contrasts between educators' reflections and student reflections (e.g., Arias Orozco et al.; LaVelle \& Yang; Lovato \& Graham) illustrate the pluralities of structured and semi-structured reflective approaches used in an educational context with a focus on making the course and its individual experiences as impactful and meaningful as possible.

\section{CONCLUSION}

Reading through the contributions to this volume, we are reminded that evaluation is a transdisciplinary practice influenced by ideas, concepts, principles, and theories from across multiple and diverse fields of study. As evaluators and evaluation instructors, we draw on social and behavioural sciences, evaluation models and approaches, program theories, philosophies, moral and ethical theories, and so forth, the intertwining of which has pedagogical consequences in terms of how we teach and in terms of what we teach. We bring who we are to the classroom and to the community. We teach what we know and what we aspire to become. Our reflections as teachers and evaluation practitioners are not separate from our actions (Freire, 1970). The notion of the "reflective practitioner" (Schon, 1983) speaks precisely to this complementary relationship between our thoughts and our actions, between our understanding and our practice, between what we think and what we do. Schwandt (2015) speaks about the need for aspiring evaluators (and all of us) to develop what he calls "a life of the mind for practice" (p. 143). We cannot divorce what we are doing from why we are doing it, and from what such doing entails. The theories we draw on in our field provide the moral and ethical foundation upon which we frame and shape our judgements, our actions, and our practice.

For us, a key aspiration as co-editors is to deepen critical analysis in the field of evaluation and to build a community of scholars, practitioners, and teachers who collectively challenge the moral, cultural, and practical fabric of our field. This is what these times require. Thus, while these practice notes illustrate the breadth of the field, as well as some of the less technical and more nuanced aspects of our profession, we would nonetheless like to challenge our peers to think about the social, political, cultural, and ethical impact of our work as evaluators (and teachers), not only locally in the community and in the classroom, but more globally as well. How does our work as teachers and evaluators contribute to the social good? How does our field contribute to "social betterment"? How is our field (and the work of evaluators) connected to the neoliberal agenda and to globalization? Where do our responsibilities as evaluators lie? What impact do we (and can we) hope to have on the health of our planet? How are we connected to these global crises? How do we amplify the many voices and perspectives in our work? How can we decolonize the practice of evaluation? What is our role in decolonization? 
How can our actions and our work contribute to democracy and equity? More challenging still, as teachers of evaluation (often located in faculties of education, public administration, and psychology), how do we teach our students to think about these broader, yet arguably more important critical, moral questions, while also developing their technical expertise? While we recognize the difficulty of addressing these questions, we firmly believe that the meaningfulness of our field will ultimately be measured, not by how many indicators were created and evaluated, but by our continued relevance in contributing to creating a more humane, just, and democratic future for all life on the planet.

\section{REFERENCES}

Argyris, C. (2004). Reflection and beyond in research on organizational learning. Management Learning, 35(4), 507-509. https://doi.org/10.1177/1350507604048276

Calliou, B., \& Wesley-Esquimaux, C. (2015). A wise practices approach to Indigenous community development in Canada. In C. Voyageur, L. Brearley, \& B. Calliou (Eds.), Restorying Indigenous leadership, wise practices in community development (pp. 31-59). Banff Centre Press.

Freire, P. (1970). Pedagogy of the oppressed. The Continuum International Publishing Group Inc.

Greene, M. (2005). Teaching in a moment of crisis: The spaces of imagination. The New Educator, 1(2), 77-80. https://doi.org/10.1080/15476880590934326

hooks, b. (1994). Teaching to transgress: Education as the practice of freedom. Routledge.

Schon, D. A. (1983). The reflective practitioner: How professionals think in action. Basic Books.

Schwandt, T. A. (2015). Evaluation foundations revisited: Cultivating a life of the mid for practice. Stanford University Press.

\section{AUTHOR INFORMATION}

Jill Anne Chouinard is an associate professor in the School of Public Administration at the University of Victoria. Much of her evaluation work has been conducted in culturally and socially diverse community settings, where she has extensive experience leading evaluations at the community level in the areas of education, social services, public health, and organizational learning and change. She positions evaluation as a catalyst for learning, collaboration, equity, social justice, and community change.

John M. LaVelle is an assistant professor in evaluation studies at the University of Minnesota. His research examines how universities prepare evaluators for applied work, and he has written on the intersection of job markets and university programs, techniques for recruiting evaluators, evaluator competencies, the psychology of evaluators, and how evaluators can use social science theory to inform their practice. He was awarded the American Evaluation Association's Marcia Guttentag Award in 2019. 